УДК $338.242 ; 339.972$

ББК 65.5

РИСКИ НЕСОГЛАСОВАННОСТИ ПРОМЫШЛЕННЫХ ПОЛИТИК ЕАЭС И МЕТОДИКА ОПРЕДЕЛЕНИЯ НЕПРОТИВОРЕЧИВЫХ ФОРМ ПРОМЫШЛЕННОЙ ИНТЕГРАЦИИ.

\author{
В. Л. ГУРСКИЙ \\ vhurski@yandex.ru \\ кандидат экономических наук, доцент, заведующий кафедрой экономики \\ БИП-Институт правоведения \\ Минск, Республика Беларусь
}

В статье определено, что иелями согласования промышленных политик в ЕАЭС являются: сохранение целостности страны и обеспечение экономической безопасности; реализация положительных интеграционных эффректов; снижение транзакиионных издержек. Основные риски несогласованности промышленных политик это: риски внутреннего доверия; риски внешнего давления; риски изначального дисбаланса в структуре ЕАЭС. Предложен методический комплекс определения непротиворечивых форм промышленной интеграчии, на основе целевой пространственной модели, позволяющий согласовать цели и компоненты промышленных политик, в отношении субъектов промыиленного развития государств-членов и между собой.

Ключевые слова: промышленная политика, международная интеграция, ЕАЭС, риски несогласованности, инструменты промышленной политики, целевое пространство, пространственная модель, методика согласования.

\title{
THE RISKS OF INCONSISTENT INDUSTRIAL POLICIES OF THE EAEU AND METHODOLOGY DEFINITION OF CONSISTENT FORMS OF INDUSTRIAL INTEGRATION
}

\section{L. HURSKY}

$\mathrm{PhD}$ in Economics, Associate Professor, Head of the Chair of Economics

BIP-Institute of law

Minsk, Republic of Belarus

The article defines that the objectives of harmonization of industrial policies are: preservation of the integrity of the country and ensuring economic security; implementation of positive integration effects; reducing transaction costs. The main risks of inconsistency of industrial policies are: risks of internal trust; risks of external pressure; risks of initial imbalance in the structure of the EAEU. The methodical complex of definition of consistent forms of industrial integration, on the basis of the target spatial model allowing to coordinate the purposes and components of industrial policies, concerning subjects of industrial development of the member States and among themselves is offered.

Key words: industrial policy, international integration, EAEU, inconsistency risks, industrial policy instruments, the target space, the spatial model, method agreement. 


\section{ВВЕДЕНИЕ}

Диалектическая взаимосвязь интеграционных и дезинтеграционных тенденций в сфере промышленной политики заключается в том, что, с одной стороны, коплиментарность промышленных комплексов государств-членов ЕАЭС обусловливает объективную потребность в интеграционном объединении, с другой, несогласованность промышленных политик и противоречивость интересов субъектов хозяйствования обусловливают неоднозначность интеграционных эффектов, которые могут стать преимущественно положительными лишь в результате согласования промышленных политик государств-членов интеграционного объединения. Согласование национальных промышленных политик, определено нами как динамичный, итеративный процесс взаимодействия субъектов промышленной политики по межгосударственной координации, субординации и ординации их интересов и целей. Отсюда вытекает необходимость определения объективных целей согласования промышленных политик рисков их несогласованности, разработки методологического комплекса согласования целей, форм интеграционного взаимодействия и инструментов государственной координации.

Экономическая сущность промышленной политики страны раскрывается в трудах А. Татаркина [1], В. Завадникова [2], С. Бадмаева [3], Д. Львова [4], О. С. Сухарева [5], однако они специализируются только на российской экономике. Изменение задач промышленной политики в глобализирующейся экономике описано в работах Л. Бляхмана [6], Ю. Малышева [7], М. Кротова [8], Д. Рубвальтер [9], Д. Сотников [10]. Среди Белорусских ученых проблематикой развития промышленной политики в условиях международной интеграции занимались С. С. Сидорский [11], Е. Н. Филиппенко [12], С. Ю. Солодовников [13], А. В. Готовский [14], Е. Л. Давыденко [15], А. Е. Дайнеко [16], А. В. Данильченко [17], Е. А. Семак [18], Е. В. Преснякова [19].

В основном, научные разработки в этой области касаются совершенствования методов применения отдельных инструментов регулирования развития промышленных комплексов государств-членов ЕАЭС и анализа зарубежного опыта формирования элементов институциональной среды. Общая концепция согласования промышленных политик государств-членов ЕАЭС пока отсутствует. Конкретные цели, критерии и риски данного процесса остались пока не изучены.

Цель данной работы провести анализ целей согласования промышленных политик государств-членов ЕАЭС, отражающих реальные интересы субъектов хозяйствования и связанные с ними риски, а также разработать методику определения непротиворечивых форм промышленной интеграции в ЕАЭС.

\section{РЕЗУЛЬТАТЫ И ИХ ОБСУЖДЕНИЕ}

Опираясь на утверждение Ф. Энгельса о том, что: «Экономические отношения каждого данного общества проявляются прежде всего как интересы» [20] и понимая под интересом субъекта промышленной политики «целевую направленность его деятельности на превращение осознанной потребности в удовлетворенную потребность за счет использования свойств и ресурсов, которыми он располагает или может привлечь» [21] можно утверждать, что развитие промышленной политики - это динамичный процесс взаимодействия по регулированию, соподчинению и согласованию интересов субъектов промышленной политики, в результате которого разрабатывается, принимается и реализуется государством вся совокупность подходов, методов, инструментарных средств, административно-представительных и исполнительно-координационных решений органов власти, оптимизируемые и объединяемые путем разработки долгосрочной экономической стратегии развития национального промышленного комплекса. 
Традиционная методика изучения интересов субъектов хозяйственной деятельности посредством их группировки по различным признакам (национальные, групповые, личные), с дальнейшей расстановкой приоритетов (доминирование национальных над личными или наоборот), хотя и представляет некоторый общетеоретический интерес, однако не несет никакой практической пользы. Во-первых, сами интересы не всегда четко обозначаются их носителями, а зачастую даже скрываются. Во-вторых, интересы динамичны и могут быстро меняться в зависимости от текущей конъюнктуры внешней и внутренней среды субъекта. В-третьих, попытки навязать субъектам некую научно обоснованную систему приоритетов малоэффективны. В этой связи, нами предлагается, за основу для согласования взять не сами интересы, а цели, как категорию наиболее конкретно обозначенную, увязанную с ресурсами, субъектами промышленной политики и выражающую их интересы.

Обобщив основные цели и принципы формирования ЕАЭС [22], установлено, что основными комплексными целями согласования промышленных политик являются: сохранение целостности страны и обеспечение экономической безопасности; реализация положительных интеграционных эффектов; снижение транзакционных издержек в сфере взаимной торговли и промышленной кооперации. Каждая из заявленных целей по отдельности не вызывает вопросов, отражает определенный блок интересов и ведет к развитию промышленности. Однако, будучи объединены все три цели демонстрируют высокий уровень конфликтности. Стремление к реализации интеграционных эффектов на основе развития и расширения интеграционного взаимодействия приводит к усилению взаимозависимости экономик государств-членов, усиливает риски, вызовы и угрозы их экономической безопасности, а стремление государств-членов снизить интеграционные риски, через введение нетарифных барьеров приводит к росту транзакционных издержек, что в свою очередь влечет за собой развитие негативных интеграционных эффектов и сокращение интеграционного взаимодействия.

Уровень конфликтности интересов и целей в промышленных политиках государств-членов ЕАЭС не является постоянной величиной, а напрямую связан с действием интеграционных рисков, которые можно разделить на три типа: риски внутреннего доверия, риски внешнего воздействия и риски изначального дисбаланса в структуре ЕАЭС.

Риски внутреннего доверия возникают уже на этапе артикуляции интересов и целей государственных структур и субъектов хозяйствования, которая зависит не только от реальной приоритетности потребностей, но и от их политической, индеологической, морально-нравственной интерпретации, и включают рост дезинтеграционных настроений в среде политических элит и общества, оппортунистические трактовки национальных интересов идеологически обосновывающие оппортунистическое поведение чиновников и руководителей предприятий. Иногда, даже объективные потребности могут быть интерпретированы как мнимые, а надуманные потребности приобрести статус приоритетных.

Таблица 1 - Количество препятствий, применяемых государствами-членами

\begin{tabular}{|l|c|c|c|c|}
\hline \multicolumn{1}{|c|}{ Государство-член } & Барьер & Изъятие & Ограничение & $\sum$ \\
\hline Республика Армения & 2 & 6 & 33 & 41 \\
\hline Республика Беларусь & 3 & 7 & 33 & 43 \\
\hline Республика Казахстан & 3 & 8 & 33 & 43 \\
\hline Кыргызская Республика & 0 & 7 & 33 & 40 \\
\hline Российская Федерация & 6 & 8 & 34 & 48 \\
\hline
\end{tabular}

Источник: [23]

Риски изначального дисбаланса в структуре ЕАЭС возникают в следствие значительной разницы в масштабах экономик и промышленных комплексов государств- 
членов, заведомо предопределяющей несопоставимость интеграционных эффектов для стран-партнеров и доминирование страны лидера над остальными участниками интеграционного процесса через контроль наднациональной бюрократии. Чисто математически (по сумме ожидаемых интеграционных эффектов) интересы России и стран партнеров уравнены быть не могут. Объективно, выгоды от интеграции для небольших государств-членов значительно выше, что позволяет формировать, поддерживать и эксплуатировать в своих интересах субъективный образ стран-иждивенцев.

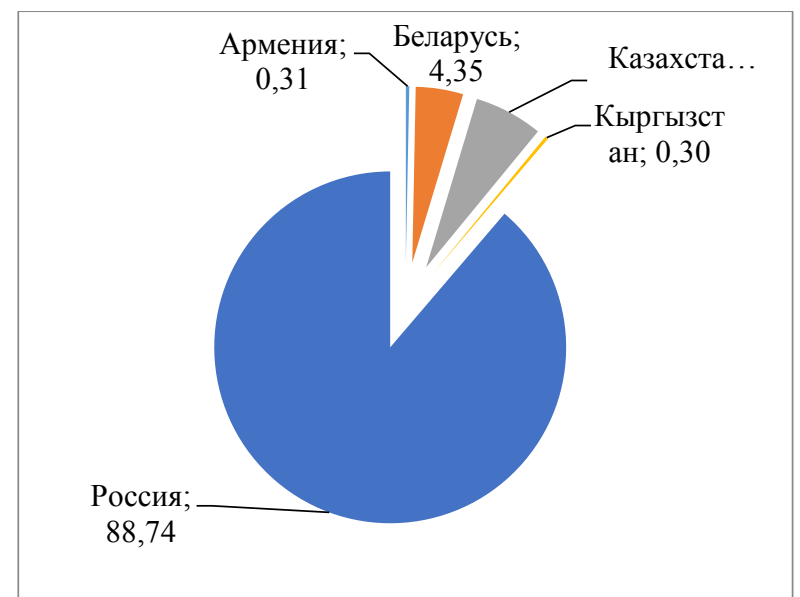

Рисунок 1 - Доля в общем объеме промышленной продукции, 2017 г. Источник: [24]

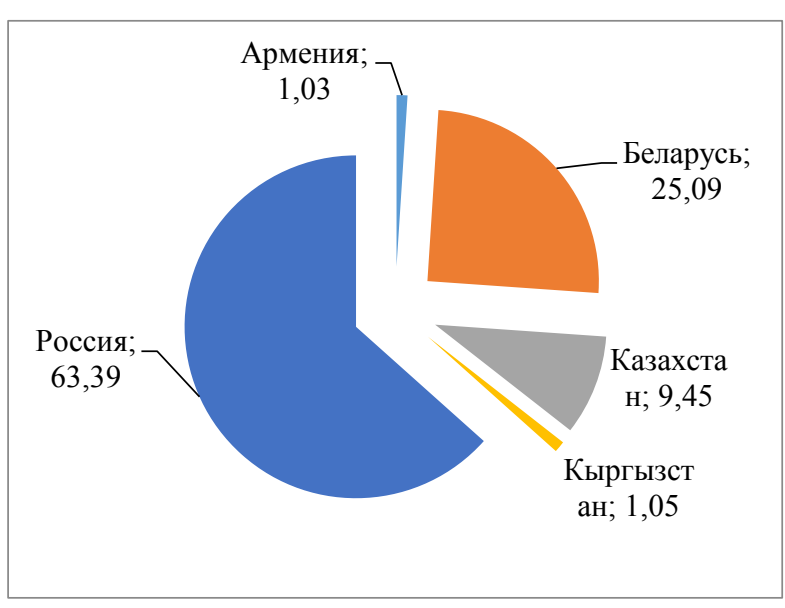

Рисунок 2 - Доля экспортных поставок во взаимной торговле государств-членов ЕАЭС, 2017 г.

Источник: [25]

Риски внешнего воздействия возникают в следствие экономико-политического влияния со стороны третьих стран и интеграционных объединений, противостояния мировых «центров силы» между собой, взаимных санкций и контрсанкций, что с одной стороны, порождает риски развития дезинтеграционных процессов, вплоть до разрушения сложившихся в ЕАЭС хозяйственных связей и снижения взаимного товарооборота, с другой стороны, значительно повышает возможность получения геоэкономической ренты для малых экономик ЕАЭС.

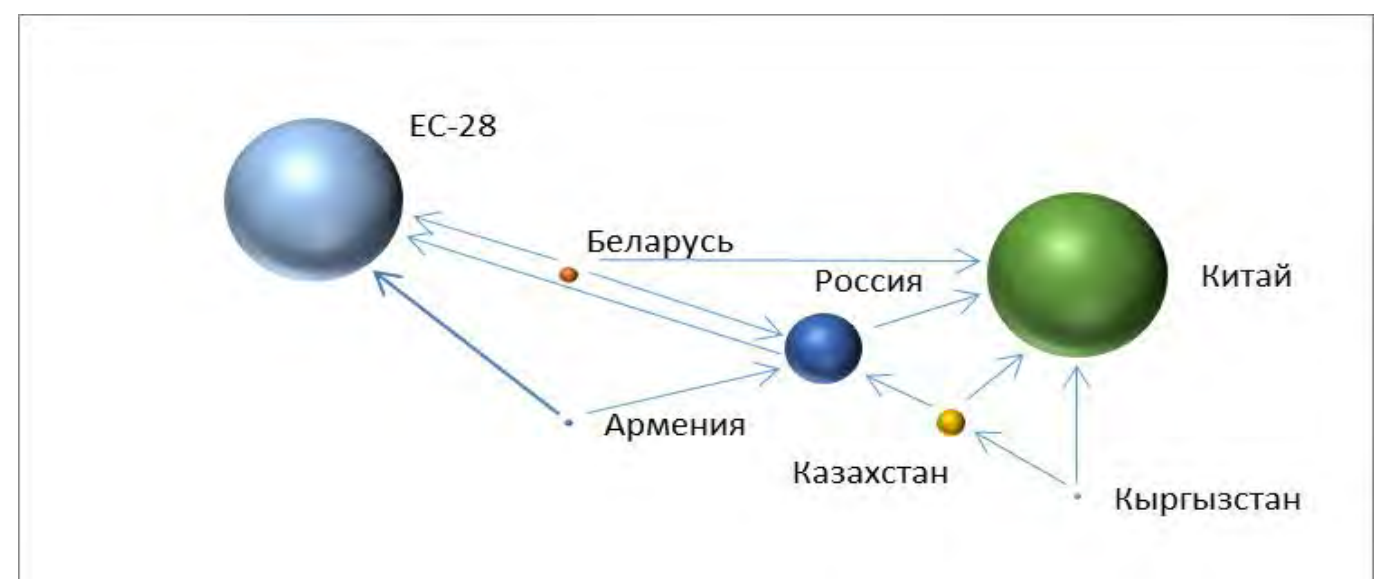

Рисунок 3 - Условная гравитационная модель основных центров притяжения на евразийском пространстве (диаметр пузырей - ВВП (по паритету покупательской способности) млрд. долл. США.

Источник: собственная разработка на основе статистических данных [26] 
Нетрудно заметить, что обозначенные группы рисков взаимосвязаны между собой и взаимодействуя с обозначенными целями согласования промышленных политик, обусловливают повышение их конфликтности. Так, риски внутреннего доверия приводят к росту транзакционных издержек в сфере взаимной торговли и промышленной кооперации; риски изначального дисбаланса масштабов экономик государств-членов ЕАЭС порождают угрозу целостности стран, их суверенитету и экономической безопасности; риски внешнего давления препятствуют достижению положительных интеграционных эффектов.

Использование инструментов промышленной политики для нейтрализации одних рисков приводит к усилению других, инструменты, направленные на достижение одних целей, приводят к сокращению возможностей реализации других целей. С точки зрения носителей интересов это явление воспринимается как игра с нулевой суммой: выигрыш одних достигается за счет проигрыша других, что вызывает конфликт инструментов промышленных политик государств-членов.

В связи с тем, что диалектическое противоречие между интеграционными интересами и рисками, являющееся одновременно и основной движущей силой развития интеграционных отношений, не может быть устранено в рамках интеграционного объединения, можно определить, что согласование промышленных политик имеет своей целью не глобальное устранение обозначенного противоречия, а поиск и реализацию возможных вариантов непротиворечивого сочетания целей, форм и инструментов промышленной политики в отношении конкретных субъектов хозяйствования.

Для решения данной задачи методология классического причинно-следственного, рационально-оптимизационного подхода, предполагающая поиск оптимального решения в виде определенного способа достижения целей, и использующаяся, в основном, при изучении замкнутых, равновесных, упрощенных систем (типа кривых проса и предложения), не применима. Наличие противоречивых целей в системе является признаком ее сложности, а такие свойства сложных систем как эквифинальность, мультифинальность и контринтуитивность предопределяют невозможность определения одного оптимального способа достижения цели для них. Иными словами, в сложных системах невозможно найти один оптимальный компромиссный вариант сочетания целевых характеристик как некую точку пересечения разнонаправленных векторов, но существует множество равновозможных вариантов достижения одинакового результата с разным сочетанием исходных условий и факторов. Исходя из этого, нами предлагается метод, позволяющий конфликтующие цели согласования промышленных политик рассматривать как целевое пространство в трехмерной системе координат, множество точек которого удовлетворяют всем трем целевым критериям в различных их сочетаниях. 


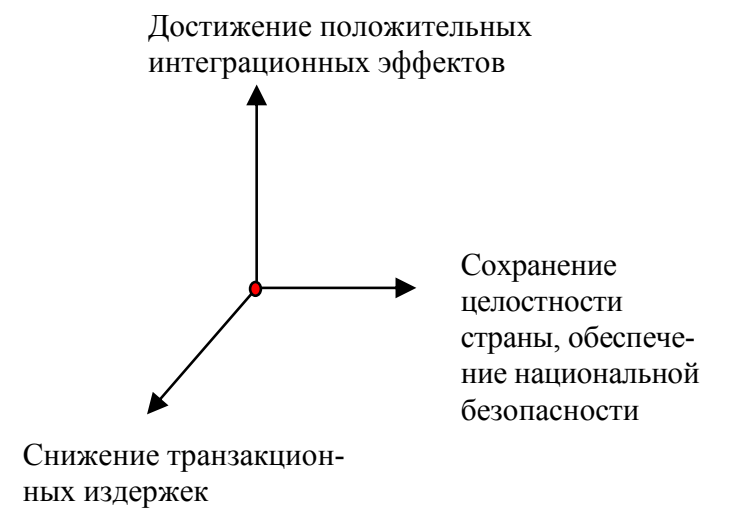

Рисунок 4 - Разнонаправленность векторов и точка противоречия интересов и целей

Источник: собственная разработка автора

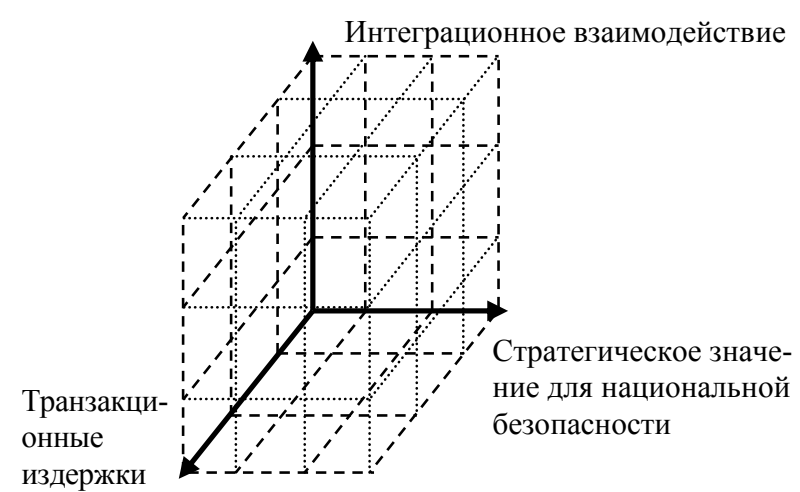

Рисунок 5 - Трехмерная пространственная модель целевого пространства согласования промышленных политик Источник:собственная разработка автора

С этой целью, нами разработан методический комплекс согласования промышленных политик включающий:

1. Методику оценки уровня стратегического значения субъектов хозяйствования, характеризующего риски экономической безопасности страны, позволяющую ранжировать субъектов на основе интегрированной количественной оценки комплекса определенных показателей.

2. Методику оценки уровня интеграционного взаимодействия субъектов хозяйствования характеризующего риски негативного действия интеграционных эффектов, позволяющую ранжировать субъектов по данному критерию.

3. Методику оценки уровня транзакционных издержек субъектов хозяйствования, характеризующего риски роста транзакционных издержек, позволяющую ранжировать субъектов по данному критерию.

4. Метод позиционирования субъектов хозяйствования в целевом пространстве трехмерной матрицы, координатными векторами которой являются интегрированные оценочные показатели по каждому из трех целевых критериев, ранжированных по трем уровням (низкий, средний и высокий) и позволяющий дифференцировать всех субъектов хозяйствования по 27 кластерам, каждый из которых характеризуется определенным сочетанием целевых критериев согласования промышленных политик.

5. Методику определения возможных вариантов непротиворечивой конфигурации интеграционных объединений и интегрированных производственных цепочек субъектов промышленной деятельности государств-членов ЕАЭС, позволяющую определить для каждого из субъектов дифференцированных ранее по 27 кластерам, критерии их интеграционного взаимодействия относительно имущественных отношений, степени централизации определенных властных полномочий, степени централизации контроля над специфическими ресурсами и сложными транзакциями.

6. Методику определения возможных вариантов адресного инструментарного комплекса в промышленной политике, позволяющую определить для каждого из субъектов, дифференцированных ранее по 27 кластерам, индивидуальный комплекс инструментов промышленных политик административного, экономического и информационного характера.

Методика оценки уровня стратегического значения субъектов хозяйствования базируется на 10 показателях, каждый из которых характеризует во сколько раз параметры 
данного субъекта, такие как объем добавленной стоимости, налоговых отчислений, инвестиций, доли экспортной продукции, численности персонала и др., выше среднереспубликанских, которые объединяются в единую интегрированную оценку, методом многофакторной средней.

Количественными критериями для выбора стратегически важных предприятий являются:

1. критерий влияния на ВВП страны (отношение среднегодовой добавленной стоимости предприятия к аналогичному среднему показателю по промышленным предприятиям в стране за последние 3 года);

2. критерий производительности труда (отношение среднегодовой добавленной стоимости, произведенной одним работником, к аналогичному среднему показателю по промышленным предприятиям в стране за последние 3 года);

3. критерий пополнения бюджета (отношение среднегодового размера налоговых отчислений к аналогичному среднему показателю по промышленным предприятиям в стране за последние 3 года);

4. критерий внутреннего мультипликатора (отношение доли комплектующих, сырья и материалов, используемых предприятием, производимых в ЕАЭС, в общей стоимости выпущенной предприятием продукции, к аналогичному среднему показателю по промышленным предприятиям в стране, за последние 3 года);

5. критерий инвестиционной активности (отношение общей суммы инвестиций в основные фонды предприятия к аналогичному среднему показателю по промышленным предприятиям в стране за последние 3 года);

6. критерий инновационной активности (отношение среднегодового выпуска научно-технической и инновационной продукции предприятия к аналогичному среднему показателю по промышленным предприятиям в стране за последние 3 года);

7. критерий влияния на экспортную квоту (отношение доли экспортной продукции в общем объеме производства предприятия, к экспортной квоте по стране в целом за последние 3 года);

8. критерий влияния на импортную квоту (отношение доли импортных комплектующих, сырья и материалов) в общей стоимости производства предприятия, к импортной квоте по стране в целом, за последние 3 года);

9. критерий сохранения трудовых ресурсов (отношение среднегодовой численности персонала к аналогичному среднему показателю по промышленным предприятиям в стране, за последние 3 года);

10.критерий доходов населения (отношение среднемесячной заработной платы персонала к аналогичному среднему показателю по промышленным предприятиям в стране за последние 3 года);

Полученные при расчете предложенных критериев показатели, по сути, показывают во сколько раз уровень данного предприятия превышает среднереспубликанский. Сравнение со среднереспубликанским значением обусловлено простым математическим правилом, если к сумме добавить число выше среднего, то среднее новой суммы увеличится, если ниже среднего, то уменьшится. Соответственно, любое предприятие с параметрами выше среднего способствует росту показателей по заданным критериям, и чем выше данное превышение, тем более значимым для развития экономики является предприятие.

Интегрированную количественную оценку общего уровня значимости для дальнейшего ранжирования предлагается рассчитать методом многомерной средней:

$$
\operatorname{ИOC} 3_{i}=\sum_{\mathrm{j}=1}^{10} \Pi \mathrm{C} 3 \mathrm{ji} / 10
$$


где ИОС $3_{\mathrm{i}}$ - интегрированная оценка стратегической значимости i-го предприятия;

ПСЗji - j-й показатель стратегической значимости і-го предприятия;

10 - количество показателей в системе оценки.

В соответствии с полученным значением, исследуемый субъект хозяйствования относим к одной из 3 групп: 1 - с низким уровнем (если интегрированная оценка меньше 1), 2 - со средним уровнем (интегрированная оценка от 1 до 10) и 3- с высоким уровнем стратегического значения (если интегрированная оценка выше 10).

Методики оценки уровня интеграционного взаимодействия и транзакционных издержек субъектов хозяйствования аналогичны, но каждый из них предполагает свой комплекс показателей. Для оценки интеграционного взаимодействия применены следующие критерии:

1. критерий экспортной зависимости от ЕАЭС (отношение доли экспорта продукции в страны ЕАЭС к доле всего экспорта предприятия в общем объеме реализованной продукции за последние 3 года);

2. критерий импортной зависимости от ЕАЭС (отношение доли импорта комплектующих, сырья и материалов из остальных государств-членов ЕАЭС к доле всего импорта предприятия, в общем объеме себестоимости реализованной продукции за последние 3 года);

3. критерий локализации (отношение доли комплектующих, сырья и материалов, используемых предприятием, поставляемых из остальных государств-членов ЕАЭС, к доле комплектующих, сырья и материалов, производимых и данной стране);

4. критерий кооперации в ЕАЭС (отношение доли комплектующих, сырья и материалов, используемых предприятием, поставляемых из остальных государств-членов ЕАЭС, к доле комплектующих, сырья и материалов поставляемых из третьих странах);

5. критерий инвестиционного взаимодействия (отношение доли ПИИ в основные и оборотные фонды предприятия из остальных государств-членов ЕАЭС к доле отечественных инвесторов, за последние 3 года);

6. критерий инновационного взаимодействия (отношение количества используемых на предприятии инновационных разработок, импортированных из остальных государств-членов ЕАЭС, к количеству используемых отечественных инноваций);

Для оценки транзакционных издержек применены критерии:

1. критерий расходов на транспортировку (отношение расходов предприятия на доставку готовой продукции покупателю к аналогичному среднему показателю по промышленным предприятиям в стране за последний год);

2. критерий отсрочки платежа (отношение среднегодовой дебиторской задолженности предприятия к аналогичному среднему показателю по промышленным предприятиям в стране, за последний год);

3. критерий низкой цены (отношение средней цены реализации товара в стране происхождения к средней цене товара, поставляемого предприятием в страны ЕАЭС за последний год);

4. критерий затоваривания складов (отношение запасов готовой, но нереализованной продукции на складах предприятия к месячному объему производства за последний год);

5. критерий количества поставщиков (отношение количества поставщиков комплектующих, сырья и материалов, используемых предприятием, производимых в остальных государствах ЕАЭС, к количеству поставщиков комплектующих, сырья и материалов в данной стране);

В соответствии с полученными значениями интегрированной оценки, исследуемый субъект хозяйствования также относим к группе с низким, средним или высоким уровнем для каждой целевой функции. 
Метод трехмерного позиционирования субъектов хозяйствования по трем целевым критериям, предполагает деление целевого пространства на 27 кластеров (3*3*3), координаты каждого из которых в трехмерной матрице соответствуют номеру группы, полученной при ранжировании интегрированных показателей, соответствующих 3 целевым критериям.

Субъекты хозяйствования, относящиеся к кластеру с координатами $(1 ; 1 ; 1)$, характеризуются низким уровнем стратегического значения, интеграционного взаимодействия и транзакционных издержек, как правило это малые и средние промышленные предприятия, не имеющие стратегического значения, получающие сырье и реализующие продукцию на местном рынке или рынках третьих стран, практически не связаны с контрагентами в ЕАЭС. Для предприятий кластера с координатами (3;3;3) напротив все показатели высокие, как правило это крупные промышленные предприятия, имеющие стратегическое значение, работающие на сырье импортируемом из ЕАЭС, и (или) экспортирующие значительную часть произведенной продукции на рынки ЕАЭС, работающие на новых или высококонкурентных рынках, либо в сфере государственных закупок, а также подвергающиеся санкциям или сталкивающиеся с протекционистскими барьерами.

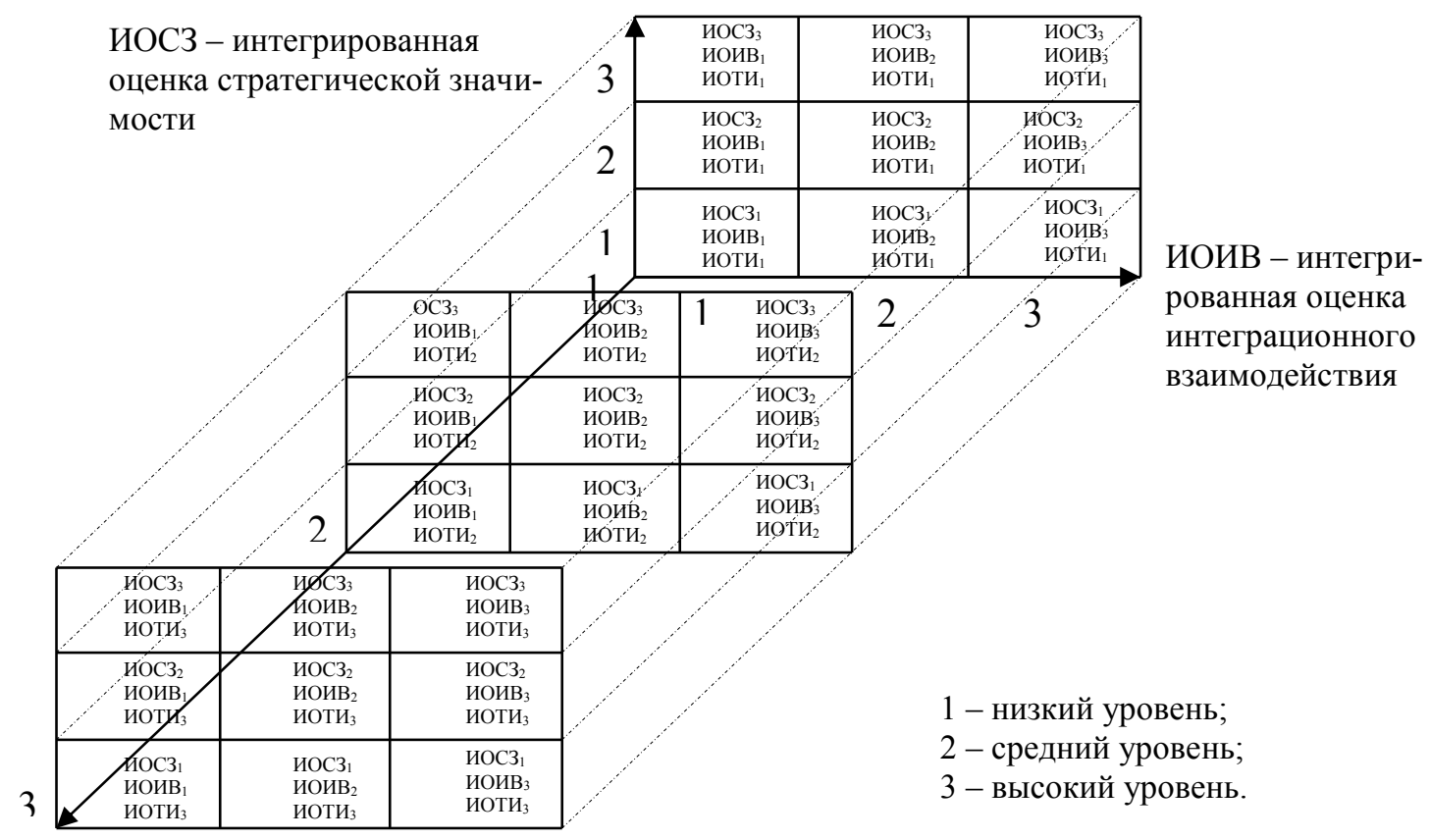

ИОТИ - интегрированная оценка транзакционных издержек

Рисунок 6 - Трехмерная матрица ранжирования субъектов хозяйствования в промышленности государств-членов, по трем целевым критериям согласования промышленной политики

Источник: собственная разработка автора

Основой предлагаемой методики определения возможных непротиворечивых вариантов конфигурации интеграционных объединений выступает выявленная взаимосвязь целевых критериев согласования промышленных политик и критериев основных типов интеграционного взаимодействия, характеризующихся степенью централизации имущественных отношений, степенью централизации определенных управленческих 
функций, степенью централизации контроля над специфическими ресурсами и сложными транзакциями.

Стратегическая значимость субъекта хозяйствования и связанные с ней риски предопределяют готовность или неготовность государства-члена передать контроль над ним (в виде контрольного пакета акций, или полной продажи) иностранному инвестору, соответственно данный критерий определяет степень интеграции на основе имущественных отношений. Определено, что чем меньше стратегическая значимость, тем меньше интерес государства к сохранению контроля над ним и тем выше возможность реализации «жестких» организационных форм интеграции компаний с зарубежным организационным центром (холдинг, ФПГ, трест, конгломерат и концерн), и напротив, чем выше стратегическая значимость предприятия, тем выше интерес государства к сохранению контроля над ним, и тем выше эффективность реализации «мягких» организационных форм интеграции компаний (кластер, консорциум, картель, синдикат, стратегические альянсы), позволяющих мобилизовать преимущества ТНК при сохранении национальной обособленности ее членов. Выявленная закономерность может быть отражена в виде вектора имущественных отношений в матрице определения непротиворечивых форм интегрирования субъектов хозяйствования согласующимся с вектором стратегического значения предприятия в предыдущей матрице.

Степень интеграционного взаимодействия и связанные с ней риски, предопределяют интересы субъектов хозяйствования объединять усилия с зарубежными партнерами в определенных сферах хозяйственной деятельности (производстве, логистике, сбыте, финансах и т. д), соответственно данный критерий определяет степень интеграции на основе добровольной централизации участниками соответствующих управленческих функций.

Определено, что чем меньше степень интеграционного взаимодействия, тем ниже интерес у субъектов хозяйствования к совместным действиям и тем меньше сфер деятельности и на меньший срок будет интегрировано, т. е. выше вероятность реализации временных организационных форм интеграции с объединением одной функции (консорциум, синдикат, стратегический альянс), а чем выше степень интеграционного взаимодействия, тем выше интерес субъектов хозяйствования к совместным действиям в различных направлениях и тем выше вероятность реализации долговременных организационных форм горизонтальной интеграции с объединением нескольких функций (холдинг, концерн, ФПГ, трест). Выявленная закономерность может быть отражена в виде вектора централизации управленческих функций в матрице определения непротиворечивых форм интегрирования субъектов хозяйствования согласующимся с вектором интеграционного взаимодействия предприятия в предыдущей матрице.

Уровень транзакционных издержек, и связанные с ним риски, предопределяют интересы субъектов хозяйствования к централизации управления с зарубежными партнерами в наиболее затратных сферах хозяйственной деятельности (снабжение дефицитными ресурсами, логистике и сбыте продукции, взаиморасчетах), соответственно данный критерий определяет степень интеграции на основе централизации контроля над специфическими ресурсами и сложными транзакциями. 


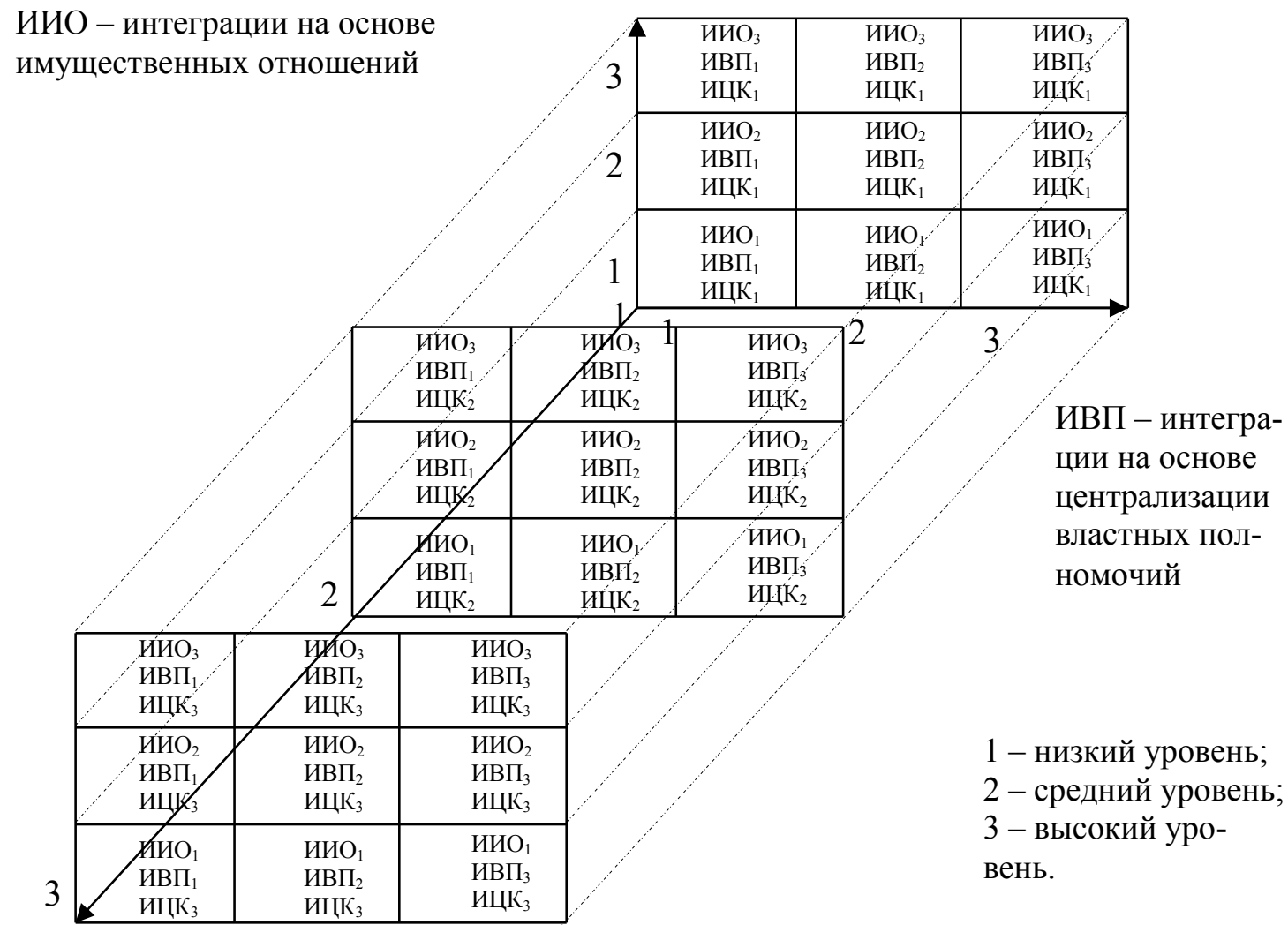

ИЦК - интеграции на основе централизации контроля над специфическими ресурсами и сложными транзакциями

Рисунок 7 - Трехмерная матрица непротиворечивых вариантов конфигурации интеграционных объединений субъектов хозяйствования в промышленности Источник: собственная разработка автора

Объединив выявленные закономерности в виде трех векторов, получим трехмерную матрицу возможных вариантов интеграционного взаимодействия комплиментарную полученной ранее матрице целевых приоритетов промышленной политики, позволяющую определить для каждого субъекта промышленной деятельности, идентифицированного ранее по целевым критериям, возможные, непротиворечащие целям, формы конфигурации интеграционных объединений (корпорация, кластер, консорциум, холдинг, концерн, ФПГ, трест, картель, синдикат, стратегические альянсы).

Методика определения адресного инструментарного комплекса в промышленной политике, сочетающего инструменты административного, экономического и информационного характера, базируется на принципе целесообразности применения тех или иных инструментов, в зависимости от сочетания соответствующих целевых характеристик субъекта хозяйствования и интеграционных рисков. 




Рисунок 8 - Трехмерная матрица определения адресного инструментарного комплекса в промышленной политике

Источник: собственная разработка автора

Стратегическая значимость субъекта хозяйствования, и связанные с ней риски, предопределяют необходимость административных инструментов воздействия. Степень интеграционного взаимодействия, и связанные с ней риски, предопределяют необходимость информационной поддержки. Уровень транзакционных издержек и связанные с ней риски, предопределяют зависимость субъектов хозяйствования от экономических инструментов государственной поддержки.

Объединив эти три закономерности методом пространственного позиционирования, получим трехмерную матрицу различных сочетаний инструментов промышленной политики комплиментарную полученной ранее матрице целевых приоритетов, позволяющую определить для каждого субъекта промышленной деятельности, адресную конфигурацию инструментарного комплекса промышленной политики, соответствующую его целевым характеристикам и рискам.

\section{ВЫВОДЫ}

Таким образом, основными комплексными целями согласования промышленных политик являются: сохранение целостности страны и обеспечение экономической без- 
опасности; реализация положительных интеграционных эффектов; снижение транзакционных издержек в сфере взаимной торговли и промышленной кооперации. Каждая из поставленных целей согласования промышленных политик имеет в своей основе ряд конкретных экономических интересов, реализация каждого из которых связана с определенными рисками. Основные группы рисков несогласованности промышленных политик государств-членов ЕАЭС это: факторы внутреннего доверия, включая рост дезинтеграционных настроений в среде политических элит и общества и оппортунистические трактовки национальных интересов государств-членов ЕАЭС; факторы внешнего давления, включающие экономическое притяжение со стороны других центров силы в регионе, геоэкономическую конъюнктуру острой фазы противостояния мировых «центров силы», санкции и контрсанкции; факторы изначального дисбаланса в конструкции ЕАЭС, включающие огромную разницу в масштабах экономик и промышленных комплексов государств-членов, несопоставимость эффектов (выигрыша и риска) для экономик странпартнеров, естественное доминирование страны лидера над остальными участниками интеграционного процесса.

Разработанный методический комплекс позволяет для каждого субъекта хозяйствования, заинтересованного в развитии интеграционных взаимосвязей либо в отношении которого проявлен интеграционный интерес, определить его место в системе координат интеграционных интересов и рисков, определить возможную для него непротиворечивую конфигурацию интеграционных объединений или интегрированных производственных цепочек, а также установить индивидуальный комплекс инструментов промышленной политики. Исходя из определения понятия промышленной политики как системы принципов, целей и инструментов государственной координации экономического процесса в промышленности, можно утверждать, что данный методический комплекс позволяет согласовать цели и компоненты промышленных политик, в отношении субъектов промышленного развития государств-членов и между собой.

\section{СПИСОК ИСПОЛЬЗОВАННЫХ ИСТОЧНИКОВ}

1. Татаркин, А. И. Промышленная политика и механизмы ее реализации: системный подход / А. И. Татаркин, О. А. Романова // Экономика региона, 2007. - № 3. - С. 19-31.

2. Завадников, В. О промышленной политике Российской Федерации // Общество и экономика, 2007. - № 3. - С. 5-39.

3. Бадмаев, С. В. Формирование модели инновационно-промышленной политики России / С. В. Бадмаев // ЭКО. - № 4. - 2007. - С. 17-52.

4. Львов, Д. С. Новая промышленная политика России / Д. С. Львов // Экон. наука соврем. России. - 2007. - N 3. - С. 9-12.

5. Сухарев, О. С. Индустриальная политика и развитие промышленных систем / О. С. Сухарев, Е. Н. Стрижакова // Национальные интересы: приоритеты и безопасность. 2014. - № 15. - С. 2-21.

6. Бляхман, А. А. Промышленная политика - основа перехода к новой модели экономического роста / А. А. Бляхман // Проблемы современной экономики. - 2013. № 1. - C. 7-17.

7. Малышев, Ю. А. Новая парадигма региональной промышленной политики / Ю. А. Малышев, А. И. Камалов // Вестник Пермского университета. Серия: Экономика. - 2011. - № 1. - С. 7-23.

8. Кротов, М. И. Проблемы модернизации экономики России в условиях евразийской интеграции / М. И. Кротов // Проблемы современной экономики. - 2013. - № 1. C. $18-21$. 
9. Рубвальтер, Д. Промышленная политика: проблемы выработки приоритетов // Власть. - 2007. - № 12. - С. 27-37.

10. Сотников, Д. М. Критерии выбора приоритетов государственной промышленной политики // «Вестник МГУ», Серия «Экономика», № 1, 2007 г. - С. 17-32.

11. Сидорский, С. С. Промышленное сотрудничество в ЕАЭС - мощный фактор экономического развития [Электронный ресурс] / Республика. - Минск, 2015. - Режим доступа: http://respublika.sb.by/obshchestvo-27/article/promyshlennoe-sotrudnichestvo-veaes-moshchnyy-faktor-ekonomicheskogo-razvitiya.html. - Дата доступа: 20.12.2015.

12. Филиппенко, Е. Н. Промышленная политика в транзитивной экономике / Е. Филиппенко // Журнал международного права и международных отношений. - 2010. № 2. - С. 22-26.

13. Солодовников, С. Ю. Понятие промышленной политики / М. С. Белявская, С. Ю. Солодовников // Устойчивое развитие экономики: состояние, проблемы, перспективы. Сборник трудов IX Международной научно-практической конференции. - Полесский государственный университет. - Пинск, 2015. - С. 11-12.

14. Готовский, А. В. Промышленная политика в Евразийской интеграции / А. В. Готовский // Евразийская экономическая интеграция. - № 1 (26). - Москва, 2015. C. 39-65.

15. Давыденко, Е. Л.Экономический вектор развития лёгкой промышленности Республики Беларусь в контексте требований ВТО / Е.Л. Давыденко // Беларусь в современном мире: материалы IV Респ. науч. конф., 28 сентября 2005 г. / редкол.: А. В. Шарапо [и др.]. - Минск: РИВШ, 2005. - С. 146-147.

16. Дайнеко, А. Е. Модернизация: приоритеты и содержание [Электронный ресурс] / А. Е. Дайнеко. - Экономика Беларуси. - № 1, 2013 г. - Режим доступа: http://economics.basnet.by/files/ru_01-13-01.pdf . - Дата доступа: 10.03.2018.

17. Данильченко, А. В. Экономическая интеграция. Интернационализация производства / А. В. Данильченко, Л. М. Петровская // Мировая экономика : курс лекций / Л. М. Петровская. - Минск : БГУ, 2002. - С. 25-56.

18. Семак, Е. А. Участие Республики Беларусь в формировании единого экономического евразийского пространства. / Е. А. Семак. // EDU. - № 3, октябрь, 2011. - М.: Открытый евразийский институт, 2011. - С. 18-23.

19. Преснякова Е. В. Влияние промышленных специфических субсидий государств-членов ЕАЭС на состояние внешней торговли Республики Беларусь. - С. 191-193. [Электронный ресурс] / Институт экономики НАН Беларуси. - Режим доступа: http://elib.bsu.by/bitstream/123456789/163278/1/presnyakova_BMW_2016.pdf. - Дата доступа: 10.03.2018.

20. Маркс, К. Сочинения: в 39 т. Изд. второе., / К. Маркс, Ф. Энгельс. - Москва: Государственное издательство политической литературы, 1955-1974. - Т. 18. - С. 271

21. Чернецова, Н. С. Экономические интересы в условиях кооперации как формы организации труда / Н. С.Чернецова, В. А. Канакина // Известия ПГПУ им. В. Г. Белинского. - Пермь, 2012. - № 28. - С. 605-608.

22. Договор о Евразийском экономическом союзе (г. Астана, от 29 мая 2014 года) [Электронный ресурс] / Официальный сайт Мин. экономики Респ. Беларусь. - Минск, 2014. - Режим доступа: http://economy.gov.ru/minec/about/structure/depsng/ agreement-eurasian-economic-union. - Дата доступа: 25.02.2018.

23. «Белая книга». Барьеры, изъятия и ограничения евразийского экономического союза доклад. [Электронный ресурс] / Евразийская экономическая комиссия. МОСКВА, 2017. - 38 с. - С. 11. - Режим доступа: https://barriers.eaeunion.org/api/info/ document/38/file. - Дата доступа: 25.02.2018. 
24. Объем промышленной продукции по видам экономической деятельности (в текущих ценах; в долларах США). Статистика Евразийского экономического союза. Промышленность [Электронный ресурс] / Евразийская экономическая комиссия. - Режим доступа: http://www.eurasiancommission.org/ru/act/integr_i_makroec/dep_stat/econstat/Pages/ industria.aspx. - Дата доступа: 25.02.2018.

25. Об итогах взаимной торговли товарами Евразийского экономического союза. Январь - декабрь 2017 года. / Статистика Евразийского экономического союза. Аналитический обзор 27 февраля 2018 г. [Электронный ресурс] / Евразийская экономическая комиссия. - Режим доступа: http://www.eurasiancommission.org/ru/act/integr_i_makroec/dep_ stat/tradestat/analytics/Documents/2017/Analytics_I_201712.pdf. - Дата доступа: 25.02.2018.

26. Евразийский экономический союз в цифрах: краткий статистический сборник [Электронный ресурс] / Евразийская экономическая комиссия. - Москва: 2017. - 204 с. C. 185. - Режим доступа: http://www.eurasiancommission.org/ru/act/integr_i_makroec/ dep_stat/econstat/Documents/Brief_Statistics_Yearbook_2017.pdf. - Дата доступа: 25.02.2018.

\section{REFERENCES}

1. Tatarkin, A. I. Promyshlennaya politika i mekhanizmy ee realizacii: si-stemnyj podhod / A. I. Tatarkin, O. A. Romanova // EHkonomika regiona, 2007. - № 3. - S. 19-31.

2. Zavadnikov, V. O promyshlennoj politike Rossijskoj Federacii // Obshche-stvo I ehkonomika, 2007. - № 2-3. - S. 5-39.

3. Badmaev, S. V. Formirovanie modeli innovacionno-promyshlennoj poli-tiki Rossii / S. V. Badmaev // EHKO. - № 4. - 2007. - S. 17-52.

4. L'vov, D. S. Novaya promyshlennaya politika Rossii / D. S. L'vov // Ehkon. nauka sovrem. Rossii. - 2007. - № 3. - S. 9-12.

5. Suharev, O. S. Industrial'naya politika i razvitie promyshlennyh sistem / O. S. Suharev, E. N. Strizhakova // Nacional'nye interesy: prioritety i bezopas-nost'. - 2014. - № 15. - C. 2-21

6. Blyahman, A. A. Promyshlennaya politika - osnova perekhoda k novoj modeli ehkonomicheskogo rosta / A. A. Blyahman // Problemy sovremennoj ehkonomiki. - 2013. - № 1. S. 7-17.

7. Malyshev, Yu. A. Novaya paradigma regional'noj promyshlennoj politiki / Yu. A. Malyshev, A. I. Kamalov // Vestnik Permskogo universiteta. Seriya: Ehkonomi-ka. 2011. - № 1. - S. 7-23.

8. Krotov, M. I. Problemy modernizacii ehkonomiki Rossii v usloviyah evrazijskoj integracii / M. I. Krotov // Problemy sovremennoj ehkonomiki. - 2013. - № 1. - S. 18-21.

9. Rubval'ter, D. Promyshlennaya politika: problemy vyrabotki prioritetov // Vlast'. 2007. - № 12. - S. 27-37.

10. Sotnikov, D. M. Kriterii vybora prioritetov gosudarstvennoj promysh-lennoj politiki // «Vestnik MGU», Seriya «EHkonomika», № 1, 2007 g. - S. 17-32.

11. Sidorskij, S. S. Promyshlennoe sotrudnichestvo v EAEHS - moshchnyj fak-tor ehkonomicheskogo razvitiya [EHlektronnyj resurs] / Respublika. - Minsk, 2015. - Rezhim dostupa: http://respublika.sb.by/obshchestvo-27/article/promyshlennoe-sotrudnichestvo-veaes-moshchnyy-faktor-ekonomicheskogo-razvitiya.html. - Data dostupa: 20.12.2015.

12. Filippenko, E. N. Promyshlennaya politika v tranzitivnoj ehkonomike / E. Filippenko // Zhurnal mezhdunarodnogo prava i mezhdunarodnyh otnoshenij. - 2010. - № 2. - S. 22-26.

13. Solodovnikov, S. Yu. Ponyatie promyshlennoj politiki / M. S. Belyavskaya, S. Yu. Solodovnikov // Ustojchivoe razvitie ehkonomiki: sostoyanie, problemy, per-spektivy. Sbornik trudov IX Mezhdunarodnoj nauchno-prakticheskoj konferencii. - Polesskij gosudarstvennyj universitet. - Pinsk, 2015. - S. 11-12. 
14. Gotovskij, A. V. Promyshlennaya politika v Evrazijskoj integracii / A. V. Gotovskij // Evrazijskaya ehkonomicheskaya integraciya. - № 1 (26). - Moskva, 2015. - S. 39-65.

15. Davydenko, E. L. Ehkonomicheskij vektor razvitiya lyogkoj promyshlennosti Respubliki Belarus' v kontekste trebovanij VTO / E. L. Davydenko // Belarus' v so-vremennom mire: materialy IV Resp. nauch. konf., 28 sentyabrya 2005 g. / redkol.: A. V. Sharapo [i dr.]. Minsk: RIVSH, 2005. - S. 146-147.

16. Dajneko, A. E. Modernizaciya: prioritety i soderzhanie [EHlektronnyj resurs] / A. E. Dajneko. - Ehkonomika Belarusi. - № 1, 2013 g. - Rezhim dostupa: http://economics.basnet.by/files/ru_01-13-01.pdf .- Data dostupa: 10.03.2018.

17. Danil'chenko, A. V. Ehkonomicheskaya integraciya. Internacionalizaciya proizvodstva / A. V. Danil'chenko, L. M. Petrovskaya // Mirovaya ehkonomika : kurs lekcij / L. M. Petrovskaya. - Minsk : BGU, 2002. - S. 25-56.

18. Semak, E. A. Uchastie Respubliki Belarus' v formirovanii edinogo ehkono-micheskogo evrazijskogo prostranstva. / E. A. Semak. // EDU. - № 3, oktyabr', 2011. - M.: Otkrytyj evrazijskij institut, 2011. - S. 18-23.

19. Presnyakova, E. V. Vliyanie promyshlennyh specificheskih subsidij gosu-darstvchlenov EAEHS na sostoyanie vneshnej torgovli Respubliki Belarus'. - S. 191-193. [Ehlektronnyj resurs] / Institut ehkonomiki NAN Belarusi. - Rezhim do-stupa: http://elib.bsu.by/bitstream/123456789/163278/1/presnyakova_BMW_2016.pdf. - Data dostupa: 10.03.2018.

20. Marks, K. Cochineniya: v 39 t. Izd. vtoroe., / K. Marks, F. Ehngel's. - Moskva: Gosudarstvennoe izdatel'stvo politicheskoj literatury, 1955-1974. - T. 18. - S. 271

21. Chernecova, N. S. Ehkonomicheskie interesy v usloviyah kooperacii kak formy organizacii truda / N. S. Chernecova, V. A. Kanakina // Izvestiya PGPU im. V. G. Belinskogo. Perm', 2012. - № 28. - S. 605-608.

22. Dogovor o Evrazijskom ehkonomicheskom soyuze (g. Astana, ot 29 maya 2014 goda) [Ehlektronnyj resurs] / Oficial'nyj sajt Min. ehkonomiki Resp. Belarus'. - Minsk, 2014. Rezhim dostupa: http://economy.gov.ru/minec/about/structure/depsng/ agreement-eurasianeconomic-union. - Data dostupa: 25.02.2018.

23. «Belaya kniga». Bar'ery, iz"yatiya i ogranicheniya evrazijskogo ehkonomicheskogo soyuza doklad. [Ehlektronnyj resurs] / Evrazijskaya ehkonomicheskaya komissiya. MOSKVA, 2017. - 38 s. - S. 11. - Rezhim dostupa: https://barriers.eaeunion.org/api/info/ document/38/file. - Data dostupa: 25.02.2018.

24. Ob"em promyshlennoj produkcii po vidam ehkonomicheskoj deyatel'nosti (v tekushchih cenah; v dollarah SSHA). Statistika Evrazijskogo ehkonomicheskogo soyuza. Promyshlennost' [Ehlektronnyj resurs] / Evrazijskaya ehkonomicheskaya komissiya. - Re-zhim dostupa: http://www.eurasiancommission.org/ru/act/integr_i_makroec/dep_stat/ econstat/ Pages/industria.aspx. - Data dostupa: 25.02.2018.

25. Ob itogah vzaimnoj torgovli tovarami Evrazijskogo ehkonomicheskogo soyu-za. Yanvar' - dekabr' 2017 goda. / Statistika Evrazijskogo ehkonomicheskogo soyuza. Analiticheskij obzor 27 fevralya 2018 g. [EHlektronnyj resurs] / Evrazijskaya ehkono-micheskaya komissiya. - Rezhim dostupa: http://www.eurasiancommission.org/ru/ act/integr_i_makroec/ dep_stat/tradestat/analytics/Documents/2017/Analytics_I_201712.pdf. - Data dostupa: 25.02.2018.

26. Evrazijskij ehkonomicheskij soyuz v cifrah: kratkij statisticheskij sbornik [Ehlektronnyj resurs] / Evrazijskaya ehkonomicheskaya komissiya. - Moskva: 2017. - 204 s. - S. 185. Rezhim dostupa: http://www.eurasiancommission.org/ru/act/integr_i_makroec/ dep_stat/econstat/Documents/Brief_Statistics_Yearbook_2017.pdf. - Data do-stupa: 25.02.2018.

Статья поступила в редакциию 19 марта 2018 года. 